387

\section{POLYUNSATURATED FATTY ACIDS IN COLOSTRUM AND COGNITIVE DEVELOPMENT IN BREASTFED CHILDREN OF THE EDEN MOTHER-CHILD COHORT STUDY}

doi:10.1136/archdischild-2012-302724.0387

1,2 JY Bernard, ${ }^{1,2} \mathrm{M}$ de Agostini, ${ }^{1,2} \mathrm{~A}$ Forhan, ${ }^{3,4} \mathrm{C}$ Garcia, ${ }^{3,4} \mathrm{M}$ Armand, ${ }^{5,6} \mathrm{M}$ Bonet, ${ }^{5,6} \mathrm{~L}$ Marchand, 5,6B Blondel, 5,6V Champion, 5,6 M Kaminski, 1,2B de LauzonGuillain, 1,2MA Charles, 1,2B Heude, EDEN Mother-Child Cohort Study Group. ' ${ }^{1}$ Center for Research in Epidemiology and Population Health, Inserm, Villejuif; 'Faculté de Médecine, Université Paris-Sud 11, Le Kremlin-Bicêtre; ${ }^{3}$ Center for Magnetic Resonance in Biology and Medicine, CNRS UMR 7339; 'Faculté de Médecine de la Timone, Université Aix Marseille, Marseille; ${ }^{5}$ Epidemiological Research Unit on Perinatal Health and Women's and Children's Health, Inserm Unit 953; ${ }^{\circ}$ Université Pierre et Marie Curie, Université Paris 6, Paris, France

Background and Aims Epidemiological studies suggest that breastfeeding could be beneficial for child cognitive development, but pathways involved remain to be elucidated. We aimed to investigate the potential role of breast milk content in polyunsaturated fatty acids (PUFAs), by studying their associations with later cognitive development.

Methods We analyzed lipid contents of colostrum samples collected from 613 breastfeeding mothers of the EDEN mother-child cohort. Cognitive development at 3 years was assessed with the Ages and Stages Questionnaire (ASQ, score between 0 and 300). We investigated associations between colostrum PUFAs and ASQ score using multiple linear regressions adjusted for centre, child's age, gender and gestational age, maternal tobacco and alcohol consumptions, parental education, siblings, caregivers, preschool attendance and exclusive breastfeeding duration.

Results Mean ASQ score was $274.2( \pm 25.1)$. Total PUFAs and $n-6$ PUFAs means were respectively $14.3 \%( \pm 2.0)$ and $12.1 \%( \pm 1.9)$ of total lipids in colostrum. Mean $n-6 / n-3$ ratio was 5.7 ( \pm 1.3 ). After adjustment, ASQ score was negatively associated with total PUFAs $(\beta=-1.8[-2.8 ;-0.8]), n-6$ PUFAs $(-1.95[-3.0 ;-0.9])$ and $n-6 / n-3$ ratio $(-1.7[-3.3 ;-0.2])$. No association was found with $n-3$ PUFAs. Associations did not differ according to breastfeeding duration $\left(P_{\text {interaction }}>0.57\right)$.

Conclusions After adjustment for confounders, especially maternal education, colostrum content in $n-6$ PUFA was negatively associated with child cognitive development, independently of exclusive breastfeeding duration. These results suggest that $n-6$ PUFAs provided in excess might compete with $n$ - 3 PUFAs biosynthesis necessary for early brain maturation and impact negatively on later cognitive development.

\section{THE PRESCHOOLERS ACTIVITY TRIAL (PAT): A RANDOMIZED CONTROLLED TRIAL OF PHYSICAL ACTIVITY INTERVENTION IN THE EARLY YEARS}

\section{doi:10.1136/archdischild-2012-302724.0388}

1,2,3GS Goldfield, 'A Harvey, ' $\mathrm{K}$ Grattan, ${ }^{1} \mathrm{R}$ Colley, ${ }^{3} \mathrm{AS}$ Alberga, $1,3 \mathrm{ZM}$ Ferraro,

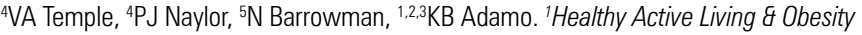
Research Group, Children's Hospital of Eastern Ontario (CHEO), Research Institute; ${ }^{2}$ Department of Paediatrics; ${ }^{3}$ School of Human Kinetics, University of Ottawa, Ottawa, ON: ${ }^{4}$ School of Exercise Science, Physical \& Health Education, University of Victoria, Victoria, BC; ${ }^{5}$ Clinical Research Unit, Children's Hospital of Eastern Ontario (CHEO), Research Institute, Ottawa, ON, Canada

Background Physical activity (PA) provides widespread health benefits, including pediatric obesity prevention, but less than $10 \%$ of Canadian children meet PA guidelines and one in three are overweight or obese. Since PA levels track from childhood into adulthood, early intervention may increase the likelihood of a physically active lifestyle and associated health benefits throughout the lifespan.
Aim To evaluate the efficacy of an intervention with day care providers on volume and intensity of PA, motor skill development, and body mass index (BMI) in 3-5 year old children attending daycares.

Methods A randomized controlled trial comparing children $(n=40)$ whose daycare providers received intervention designed to promote PA versus children $(n=43)$ whose providers implemented the normal preschool curriculum. Intervention included two, 3-hour workshops plus 12 bi-monthly "booster" sessions. Children were assessed at baseline and 3-months, with a plan to collect data at 6-months. PA was measured objectively using accelerometry. Motor skills were measured using the Test of Gross Motor Development-2. BMI was assessed by measured heights and weights $\left(\mathrm{kg} /\right.$ metres $\left.^{2}\right)$

Results Compared to controls, the intervention produced greater increases in mean steps/day ( -83 vs. $+1,185, p<0.01)$, gross motor percentile scores $(+6 \mathrm{vs} .+16, \mathrm{p}<0.05)$ and reductions in BMI $(+0.21$ vs $-0.22, \mathrm{p}<0.001)$ at 3 -months but not moderate to vigorous $\mathrm{PA}$ (MVPA).

Conclusions Intervening with daycare providers may be an efficacious method of increasing preschoolers' volume of PA, promoting motor skill development that is critical to PA and sport participation later in life, and reducing adiposity.

\section{IS THE HIGHER PREVALENCE OF ASTHMATIC SYMPTOMS FOLLOWING PRETERM BIRTH RESTRICTED TO CHILDHOOD?}

doi:10.1136/archdischild-2012-302724.0389

${ }^{1} \mathrm{ALDB}$ Damgaard, ${ }^{2} \mathrm{R}$ Mathiasen, ${ }^{1} \mathrm{BM}$ Hansen, ${ }^{2} \mathrm{~F}$ Buchvald, ${ }^{1} \mathrm{G}$ Greisen. 'Department of Neonatology; '2Department of Paediatrics, Copenhagen University Hospital Rigshospitalet, Copenhagen, Denmark

Background and Aim Preterm birth is associated with increased risk of asthmatic symptoms in childhood, but it seems uncertain whether this association persists into adulthood. We have investigated the association between gestational age (GA) and the use of prescription asthma medication in young adults.

Methods This is a register study of a Danish national cohort of all infants born 1980-1989 and followed up at the age of 21-30 years. The retrieval of prescription asthma medication (inhaled beta- 2 agonists and/or inhaled corticosteroids and/or oral leukotriene antagonists) in 2009-2010 was evaluated. Logistic regression analyses were performed to determine the relationship between the use of asthma medication and gestational age, adjusted for gender, small-for-gestational age and multiple births.

Results Data were obtained on 516337 individuals (72.7\% of all infants born in the period). The prevalence of asthma medication use in young adults born term was $6.33 \%$, compared to $6.91 \%$ in those born preterm. Comparing with the term group, we found slightly increased adjusted $\mathrm{OR}$ for the use of asthma medication for individuals born at GA 32-36 weeks ( $\mathrm{n}=20$ 848) OR=1.12 (95\% $\mathrm{CI}=1.06-1.18)$ and GA $28-31$ weeks ( $\mathrm{n}=2$ 256) $\mathrm{OR}=1.23(95 \%$ $\mathrm{CI}=1.05-1.44)$. In the extremely preterm group ( $\mathrm{GA}=24-27$ weeks, $\mathrm{n}=355)$ the association was not significant: $\mathrm{OR}=1.04 \quad(95 \%$ $\mathrm{CI}=0.68-1.58$ )

Conclusion There was an association between gestational age and the use of asthma medication at 21-30 years, but it was weak. The adjusted $\mathrm{OR}$ increased slightly with decreasing GA except in adults born extremely preterm. Further analyses will be performed to investigate our findings.

\section{CEREBRAL PALSY AND NEONATAL DEATH IN SINGLETONS BORN SMALL FOR GESTATIONAL AGE AT TERM}

doi:10.1136/archdischild-2012-302724.0390

1,2M Stoknes, 1.3 GL Andersen, ' $\mathrm{MO}$ Dahlseng, ' $\mathrm{J}$ Skranes, ${ }^{1,4}$ KÅ Salvesen, ${ }^{5,6} \mathrm{LM}$ Irgens, JJ Kurinczuk, 1,2T Vik. 'Department of Laboratory Medicine, Children's and Women's 